\title{
Fasting and postprandial gastrointestinal motility in ulcer and non-ulcer dyspepsia
}

\author{
V Stanghellini, C Ghidini, M Ricci Maccarini, G F Paparo, R Corinaldesi, L Barbara
}

\begin{abstract}
This study aimed to compare fasting and postprandial gastrointestinal motor patterns in patients with ulcer and non-ulcer dyspepsia. Forty five subjects were studied: 10 with uncomplicated gastric ulcer, eight with uncomplicated duodenal ulcer, 18 with chronic idiopathic dyspepsia, and nine healthy asymptomatic controls. Gastrointestinal fasting and postprandial motor patterns were recorded using a low compliance perfusion technique. The interdigestive antral cumulative motility index, computed for $\mathbf{3 0}$ minutes before the appearance of duodenal activity fronts, and the number of activity fronts with an antral component were significantly less in patients with ulcers and those with non-ulcer dyspepsia compared with asymptomatic controls. The patient groups also had a reduced antral motor response to a solid-liquid test meal compared with healthy controls. Intestinal motor abnormalities (bursts of nonpropagated phasic pressure activity and discrete clustered contractions) were recorded in a minority of patients, all with associated irritable bowel symptoms. In conclusion, antral hypomotility is a frequent but nonspecific motor abnormality in dyspepsia; abnormal motor patterns of the small bowel are less frequent and seem to be confined to patients with concomitant irritable bowel syndrome.
\end{abstract}

Dyspepsia is a common syndrome that has been defined as 'episodic or persistent abdominal symptoms, often related to feeding, which patients or physicians believe to be due to disorders of the proximal portion of the digestive tract'.'

Abnormal gastrointestinal motor patterns have been recorded in a variety of dyspeptic syndromes that are both primary (or idiopathic) and secondary to organic, systemic, and metabolic diseases. ${ }^{2}$ Specifically, antral hypomotility, alone or in combination with intestinal motor abnormalities, has been described in both ulcer ${ }^{3+}$ and non-ulcer (or idiopathic) dyspepsia. ${ }^{5-10}$ In healthy subjects, gastrointestinal motility during fasting is characterised by the interdigestive migrating motor complex, represented by the cyclic sequence of three phases: phase I of motor quiescence, phase II of irregular motor activity, and phase III, or activity front characterised by a burst of coordinated contraction propagated in an aboral direction. The antral component of phase III clears the stomach of indigestible solids" and digestive secretions. ${ }^{12}$ Interdigestive antral hypomotility has been observed in gastric ulcer patients with higher bile acid concen- trations ${ }^{4}$ and has been indicated as a possible pathogenetic factor in the disease. ${ }^{13}$ Postprandial antral contractions grind digestible solids, thus allowing the pressure gradient created by the fundus of the stomach to empty its liquid and liquefied contents into the small bowel." Retention of gastric contents occurs in patients with antral hypomotility ${ }^{14}$ and may be involved in determining dyspeptic symptoms. ${ }^{15}$ Gastrointestinal manometric studies in duodenal ulcer patients have received little interest in recent years despite the fact that accelerated gastric emptying has been proposed as a possible pathogenetic mechanism of the disease. ${ }^{16}$ No direct comparative evaluation of gastrointestinal motor patterns in ulcer and non-ulcer dyspepsia has yet been published. Our study aimed to compare fasting and postprandial gastrointestinal contractile activities in patients with chronic idiopathic dyspepsia and active uncomplicated peptic ulceration.

\section{Methods}

SUBJECTS

Thirty six consecutive patients ( 17 men and 19 women; aged 18-64 years) referred to this department because of chronic or recurrent dyspeptic symptoms entered the study after giving informed consent. Eighteen patients (seven men and 11 women; aged 18-63 years, median 31 years) had chronic idiopathic dyspepsia; 10 patients (five men and five women, aged 34-63 years, median 50 years) had active uncomplicated type 1 gastric ulcer not associated with the use of analgesics (maximal ulcer diameter: $0.5-1.5 \mathrm{~cm}$ ); and eight patients (five men and three women, aged 25-57 years, median 48 years) had active uncomplicated duodenal ulcer (maximal ulcer diameter: $0 \cdot 5-1 \cdot 0 \mathrm{~cm}$ ). Inclusion criteria were as follows:

(a) Chronic ( $>6$ months) dyspeptic symptoms with a cumulative weekly score $\geq 3$ and at least one symptom scored $\geq 2$ (see below);

(b) Evidence of uncomplicated active duodenal ulcer or type I gastric ulcer in the absence of any other focal lesion and/or oesophagitis (in ulcer dyspepsia);

(c) As above, but in the absence also of any focal lesion in the upper digestive tract (in chronic idiopathic dyspepsia patients);

(d) Absence of any other organic disease;

(e) Absence of systemic, metabolic, endocrine, neurological, and psychiatric diseases;

(f) No history of major abdominal surgery.

Inclusion criteria were verified by accurate history taking, physical examination, and appropriate laboratory investigations. The presence of active uncomplicated peptic ulcer 
TABLE I Clinical presentation of patients with duodenal ulcer, gastric ulcer, and chronic idiopathic dyspepsia

\begin{tabular}{|c|c|c|c|c|c|c|c|c|}
\hline \multirow[b]{2}{*}{ Group } & \multirow[b]{2}{*}{$\begin{array}{l}\text { Age } \\
\text { (yrs) }\end{array}$} & \multirow[b]{2}{*}{ Sex } & \multicolumn{6}{|l|}{ Symptoms } \\
\hline & & & $\begin{array}{l}\text { Epigastric } \\
\text { pain }\end{array}$ & $\begin{array}{l}\text { Postprandial } \\
\text { fullness }\end{array}$ & Vomiting & Nausea & $\begin{array}{l}\text { Changes in } \\
\text { bowel habits }\end{array}$ & $\begin{array}{l}\text { Abdominal } \\
\text { pain }\end{array}$ \\
\hline \multicolumn{9}{|c|}{ Duodenal ulcer: } \\
\hline $\mathrm{CM}$ & 25 & F & 1 & 2 & 1 & 1 & - & - \\
\hline SL & 40 & $M$ & 2 & 3 & 0 & 0 & - & - \\
\hline GGP & 41 & M & 2 & 2 & 0 & 0 & + & + \\
\hline $\mathrm{BL}$ & 45 & $\mathbf{F}$ & 3 & 1 & 0 & 1 & - & - \\
\hline GG & 51 & $M$ & 2 & 2 & 1 & 1 & - & - \\
\hline BL & 54 & $\mathrm{~F}$ & 3 & 0 & 0 & 0 & - & + \\
\hline$S C$ & 57 & $M$ & 3 & 0 & 0 & 0 & - & - \\
\hline \multirow{2}{*}{\multicolumn{9}{|c|}{ Gastric ulcer: }} \\
\hline & & & & & & & & \\
\hline BS & 34 & $\mathrm{~F}$ & 2 & 1 & 0 & 0 & + & + \\
\hline VD & 37 & $M$ & 3 & 3 & 1 & 1 & + & + \\
\hline GA & 40 & M & 3 & 0 & 0 & 0 & - & - \\
\hline $\mathrm{AA}$ & 45 & $M$ & 1 & 3 & 2 & 2 & - & - \\
\hline $\mathrm{CB}$ & 49 & $\mathrm{~F}$ & 2 & 1 & 0 & 1 & + & + \\
\hline IA & 51 & $\mathrm{~F}$ & 3 & 2 & 1 & 1 & - & - \\
\hline DCM & 57 & $\mathrm{~F}$ & 2 & 2 & 1 & 1 & - & + \\
\hline $\mathrm{FA}$ & 60 & $M$ & 2 & 2 & 0 & 0 & - & - \\
\hline BML & 63 & F & 2 & 0 & 1 & 1 & + & + \\
\hline \multirow{2}{*}{\multicolumn{9}{|c|}{$\begin{array}{l}\text { GE } \\
\text { Chronic idiopathic dyspepsia: }\end{array}$}} \\
\hline & & & & & & & & \\
\hline MF & 18 & $\vec{F}$ & 1 & 2 & 2 & 2 & + & + \\
\hline SI & 20 & $\mathrm{~F}$ & 2 & 2 & 0 & 0 & + & + \\
\hline IC & 20 & $M$ & 0 & 2 & 2 & 1 & + & + \\
\hline GMG & 22 & $F$ & 0 & 2 & 0 & 1 & - & - \\
\hline SU & 24 & $\mathrm{M}$ & 1 & 2 & 0 & 1 & + & + \\
\hline BM & 24 & $\mathrm{~F}$ & 2 & 1 & 3 & 1 & + & - \\
\hline FL & 28 & F & 2 & 2 & 2 & 1 & + & + \\
\hline BM & 31 & F & 0 & 2 & 0 & 2 & + & + \\
\hline BU & 31 & $\mathbf{M}$ & 2 & 2 & 0 & 0 & - & - \\
\hline DMR & 31 & $M$ & 2 & 2 & 1 & 1 & - & - \\
\hline VU & 33 & $\mathrm{~F}$ & 0 & 3 & 0 & 0 & + & + \\
\hline $\mathrm{CA}$ & 36 & $M$ & 2 & 2 & 0 & 0 & - & - \\
\hline $\mathrm{RA}$ & 46 & $\mathrm{~F}$ & 0 & 2 & 2 & 2 & + & + \\
\hline $\mathrm{MA}$ & 46 & $\mathrm{~F}$ & 2 & 2 & 2 & 0 & + & + \\
\hline $\mathrm{BM}$ & 49 & M & 1 & 2 & 0 & 0 & + & + \\
\hline FG & 51 & $\mathrm{~F}$ & 2 & 2 & 0 & 0 & + & + \\
\hline $\mathrm{BP}$ & 52 & $M$ & 1 & 2 & 2 & 2 & + & + \\
\hline SV & 63 & F & 1 & 2 & 0 & 0 & + & + \\
\hline
\end{tabular}

Symptom scoring: 0 =absent, 1 =occasional but not influencing normal activity, 2 =occurring moderately often and slightly influencing usual activities, $3=$ occurring moderately or more often and influencing usual activities considerably. + Present, - absent.

craters was verified by endoscopy, performed in all patients during the week preceding the manometric test. Several patients presented with features compatible with the diagnosis of irritable bowel syndrome, as defined by the concomitant presence of diffuse abdominal pain and changes in bowel habits. ${ }^{17}$ Table I reports scoring of dyspeptic symptoms and the presence of symptoms of irritable bowel syndrome.

Nine healthy asymptomatic subjects (four men and five women, aged $30-50$ years, median 33 years) served as controls. The subject groups investigated were matched for sex, but not for age. Healthy controls $(35 \cdot 3(7 \cdot 3)$ years) and chronic idiopathic dyspepsia patients $(34 \cdot 7$ $(13 \cdot 3))$ were younger than both duodenal ulcer patients $(46.2(10.9) ; \mathrm{p}<0.05$, Student's $t$ test) and gastric ulcer patients (49.9 (10.7)\%; $\mathrm{p}<0.005)$.

\section{DYSPEPTIC SYMPTOM SCORING}

A questionnaire listing four symptoms (epigastric pain, postprandial fullness, nausea, and vomiting) was completed for each patient. Symptoms were graded on a weekly basis: $0=$ absent,$\quad 1=$ occasional present and not affecting the patient's usual activities; $2=$ present moderately often and slightly affecting the usual activities; $3=$ present moderately or more often and influencing considerably the patient's usual activities. Seventy five asymptomatic volunteers also completed the questionnaire and served as controls. Among healthy subjects, cumulative scores ranged from 0 to 3 , with no symptom being graded $\geq 2$. Therefore, a total weekly symptom score $\geq 3$, with at least one symptom graded $\geq 2$, was a criterion for entry to the study.

\section{MANOMETRIC PROCEDURE}

Gastrointestinal motility was recorded by a previously validated manometric technique. ${ }^{18} \mathrm{~A}$ multilumen polyvinylchloride (PVC) probe was assembled by gluing together three triple lumen PVC catheters (Dural Plastics, NSW, Australia, internal diameter $0.96 \mathrm{~mm}$, global outside diameter $6.0 \mathrm{~mm}$ ). Eight recording channels were perfused with bubble free distilled water at a constant rate of $0.4 \mathrm{ml} / \mathrm{minute}$ by a low compliance pneumohydraulic system (Arndorfer Medical Specialties Inc, Greendale, WI, USA). Changes in pressure were transformed into electrical signals by pressure transducers (Sensormedics, 4-327-I, SM, Anaheim, CA, USA) and printed out on a paper-chart recorder (R 611 Dynograph, Beckman Instruments Inc, Anaheim, CA, USA). The probe was assembled so that when placed in position the recording sites were located across the antroduodenal junction $(5,0.9 \mathrm{~cm}$ apart $)$ and in the proximal small bowel (3,10 cm apart). Occlusion of any of the side openings produced pressure rise rates greater than $300 \mathrm{~mm} \mathrm{Hg} / \mathrm{second}$. The ninth lumen was used to inflate a balloon located at the tip of the probe and to allow a more rapid positioning of the tube: the balloon was deflated during the studies.

The subjects swallowed the tube in the morning after an overnight fast: none had been 
taking any medication for at least 48 hours. After fluoroscopic positioning of the tube, ${ }^{19}$ the subjects lay supine on a hospital bed in a single quiet room, with the head end of the bed elevated $30 \% 45^{\circ}$ to the horizontal.

Motility was recorded for $180-320$ minutes during fasting and for 60-85 minutes after ingestion of a solid-liquid balanced meal (613 $\mathrm{kcal}$; ground beef $80 \mathrm{~g}$, potatoes $150 \mathrm{~g}$, corn oil $10 \mathrm{~g}$, bread $20 \mathrm{~g}$, cream flan $100 \mathrm{~g}$, water $200 \mathrm{ml}$ ). The test meal was given at least 30 minutes after the occurrence of a phase III of the interdigestive migrating motor complex (when recorded) and, in all cases, during a period of irregular motility.

\section{ANALYSIS OF MANOMETRIC TRACINGS}

Recordings were analysed by visual inspection and the following parameters were quantitated:

(a) Total number of activity fronts, defined as bursts of high amplitude, high frequency (8-12/ minute) contractions lasting no less than three minutes, aborally propagated on at least two intestinal recording sites, and followed by a period of quiescence (phase I). The number of activity fronts with an antral component (3 waves/minute, lasting no less than two minutes) was also computed;

(b) Activity front propagation velocity from descending duodenum to proximal jejunum ports;

(c) Distal antrum interdigestive motor activity, expressed as the mean cumulative motility index (number of waves $\times$ sum of amplitudes $\times 10^{-3}$ ) during the 30 minutes preceding the beginning of duodenal activity fronts. The distal antrum was defined as the most distal recording site not exhibiting tonic increases of the baseline and registering a maximum contraction frequency of $3 /$ minute; ${ }^{20}$

(d) Distal antrum contractile response to meal ingestion expressed as the number of pressure waves (mean/10 minutes), sum of amplitudes $\times$ $10^{-2}$ (mean/10 minutes), and cumulative motility index in the postprandial (60 minute) period;

(e) Presence of abnormal motor patterns in the small bowel, during both fasting and after feeding.

Data were analysed by non-parametric tests: comparisons between groups were by Wilcoxon's rank sum test ${ }^{21}$ and correlation between postprandial antral motility and dyspeptic symptom scores by Spearman's rank correlation. ${ }^{21}$ Two tailed $p$ values less than 0.05 were considered significant.

\section{Results}

\section{FASTING PERIOD}

At least one activity front of the interdigestive migrating motor complex was observed in all but six subjects (one duodenal ulcer patient, one gastric ulcer patient, and four chronic idiopathic dyspepsia patients). Details of interdigestive motility are reported in Table II. We observed a reduced number of activity fronts with an antral component in all patient groups compared with controls $(p<0.01)$. Similarly, the cumulative motility index computed for 30 minutes before the duodenal appearance of intestinal activity fronts, was lower in duodenal ulcer $(p<0.05)$, gastric ulcer $(\mathrm{p}<0.01)$, and chronic idiopathic dyspepsia patients $(\mathrm{p}<0.01)$ than in healthy controls. No significant difference was found between the different groups of dyspeptic patients in the number of activity fronts with an antral component or in the cumulative motility index values computed in the 30 minutes before the appearance of duodenal activity fronts.

\section{POSTPRANDIAL PERIOD}

All the patient groups showed a reduction in the antral motor response to ingestion of the test meal compared with healthy controls $(\mathrm{p}<0.001)$. Figure 1 shows individual fed cumulative motility indices computed at 60 minutes in healthy controls, duodenal ulcer, gastric ulcer, and chronic idiopathic dyspepsia patients. Cumulative motility index values were significantly reduced in duodenal ulcer (mean (SD) $102 \cdot 1(60 \cdot 2) ; \mathrm{p}<0.005)$, gastric ulcer $(50 \cdot 5(30 \cdot 2)$; $\mathrm{p}<0.001$ ), and chronic idiopathic dyspepsia patients $(77.5(54.5) ; \mathrm{p}<0.001)$ compared with healthy controls $(230 \cdot 7(74 \cdot 3))$. Postprandial antral hypomotility, defined according to the $95 \%$ confidence intervals of the distribution of the cumulative motility index at 60 minutes in healthy controls, was detected in 11 chronic idiopathic dyspepsia patients (61\%), in nine gastric ulcer patients (90\%), and in four duodenal ulcer patients (50\%). Differences between the groups of dyspeptic patients did not reach statistical significance. Figure 2 shows cumulative values of the number of waves and sum of

TABLE II Duration of manometric recording and main features of interdigestive gastrointestinal motility

\begin{tabular}{|c|c|c|c|c|c|}
\hline Group & $\begin{array}{l}\text { Recording } \\
\text { duration } \\
\text { (min) } \\
\text { Range (median) }\end{array}$ & $\begin{array}{l}\text { Mean no of } \\
A F / h r\end{array}$ & $\begin{array}{l}\text { No of } A F \text { with } \\
\text { antral component } \\
(\%)\end{array}$ & $\operatorname{Mean}(S D) C M I$ & $\begin{array}{l}\text { Mean }(S D) A F \text { velocity } \\
\text { propagation from descending } \\
\text { duodenum to proximal jejunum } \\
(\mathrm{cm} / \mathrm{min})\end{array}$ \\
\hline $\begin{array}{l}\text { Healthy controls } \\
(n=9)\end{array}$ & $\begin{array}{c}230-300 \\
(240)\end{array}$ & 0.39 & $12(86)$ & $65 \cdot 9(49 \cdot 4)$ & $12 \cdot 1(8 \cdot 9)$ \\
\hline $\begin{array}{l}\text { Duodenal ulcer } \\
(\mathrm{n}=8)\end{array}$ & $\begin{array}{c}230-250 \\
(240)\end{array}$ & 0.40 & $3(23)^{\star \star}$ & $22 \cdot 2(23 \cdot 9)^{\star}$ & $10.4(1.9)$ \\
\hline $\begin{array}{l}\text { Gastric ulcer } \\
(n=10)\end{array}$ & $\begin{array}{c}240-300 \\
(240)\end{array}$ & 0.38 & $2(13)^{\star \star}$ & $20 \cdot 8(25 \cdot 7)^{\star \star}$ & $11 \cdot 0(3 \cdot 5)$ \\
\hline $\begin{array}{l}\text { Chronic } \\
\text { idiopathic } \\
\text { dyspepsia } \\
(\mathrm{n}=18)\end{array}$ & $\begin{array}{c}165-300 \\
(240)\end{array}$ & $0 \cdot 29$ & $4(20)^{\star \star}$ & $13 \cdot 5(19 \cdot 7)^{\star \star}$ & $9 \cdot 8(6 \cdot 2)$ \\
\hline
\end{tabular}


Figure 1: Postprandial cumulative motility index at 60 minutes in healthy controls and patients with

duodenal ulcer, gastric ulcer, and chronic idiopathic

dyspepsia. Bars represent

mean values $\left({ }^{\star} p<0.005 \mathrm{v}\right.$

healthy controls, $\star \star p<0.001$

$\mathrm{v}$ healthy controls).
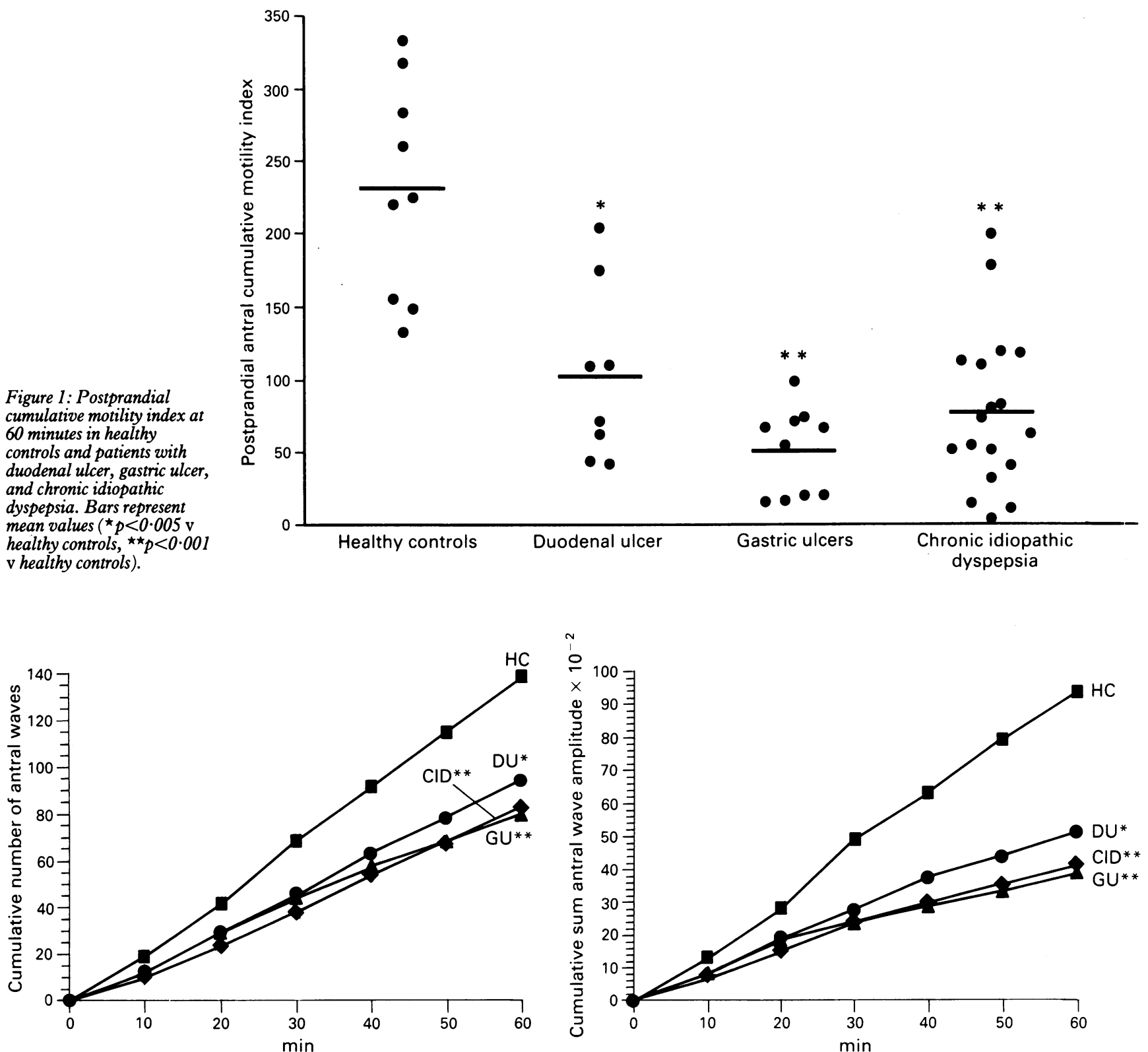

Figure 2: Postprandial cumulative number (left panel) and sum of amplitudies (right panel) of antral waves at 10 minute intervals in healthy controls (HC) and patients with duodenal ulcer $(D U)$, gastric ulcer (GU, and chronic idiopathic dyspepsia $(C I D)\left({ }^{\star} p<0.005 \mathrm{v} H C ;{ }^{\star \star} p<0.001 \mathrm{v} H C\right)$.
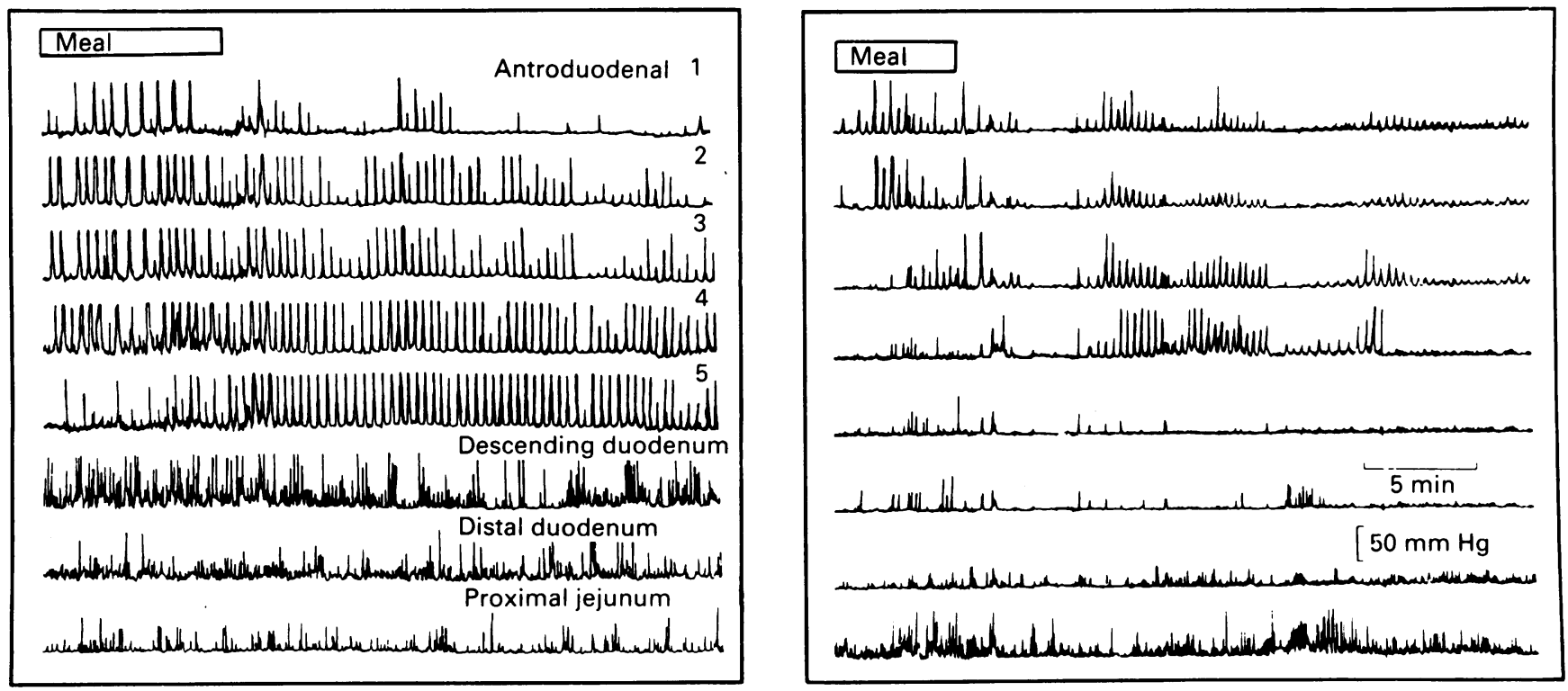

Figure 3: Gastrointestinal contractile response tofeeding in a healthy control (left panel) $(M, 32$ years) and in a patient $(M, 53$ years) with chronic idiopathic dyspepsia (right panel). The postprandial antral motility in the dyspeptic patient is characterised by infrequent low amplitude pressure waves. 


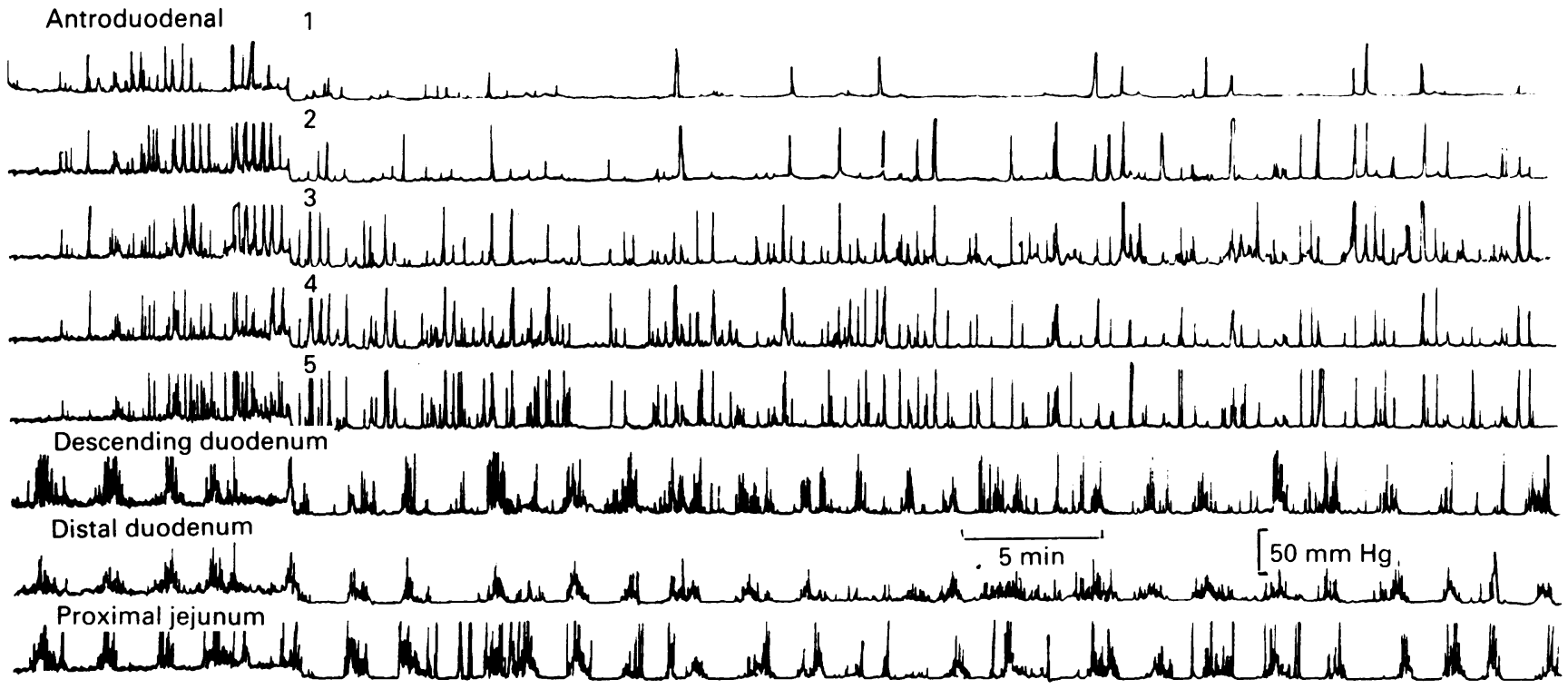

Figure 4: Postprandial recording in a patient (M, 49 years) with chronic idiopathic dyspepsia and features of irritable bowel syndrome. Groups of high amplitude, high frequency contractions separated by at least one minute of absent motor activity are apparent at the distal duodenum and proximal jejunum recording sites throughout the study.

amplitudes. No significant correlation was found between postprandial antral cumulative motility indexes and cumulative or individual weekly symptom scores. Examples of postprandial antral motility in a chronic idiopathic dyspepsia patient and in a healthy asymptomatic control are reported in Figure 3.

\section{INTESTINAL MOTOR ABNORMALITIES}

Intestinal motor abnormalities were recorded in only three patients: RA (a 46 year old woman with chronic idiopathic dyspepsia), BM (a 49 year old man with chronic idiopathic dyspepsia) and GE (a 63 year old man with gastric ulcer). RA showed a burst of non-propagated phasic pressure activity during fasting. Bursts were defined as periods of at least two minutes' duration with continuous high amplitude $(\geq 20 \mathrm{~mm} \mathrm{Hg}$ ) and high frequency (10-12/ minute) phasic pressure activity, not propagated and not followed by motor quiescence. ${ }^{22}$ Discrete clustered contractions were recorded during both the fasting and postprandial periods in patients BM and GE. This motor abnormality was defined as groups of high amplitude, high frequency contractions separated by at least one minute of absent motor activity. ${ }^{23}$ Postprandial minute clustered contractions lasted over 30 minutes (Fig 4).

\section{Discussion}

This study compared interdigestive and postprandial motor patterns in patients with chronic idiopathic dyspepsia and in patients with symptomatic peptic ulcers. Both populations of dyspepsia patients showed a noticeable decrease in fasting and postprandial antral motility. A minority of patients with associated irritable bowel syndrome also showed abnormal motor patterns in the proximal small bowel.

Decreased antral contractility seems to be a non-specific motor disorder. Antral hypomotility during fasting and postprandial periods has previously been reported in patients with diabetes $^{2+25}$ or other diseases affecting the myogenic ${ }^{26}$ or neurogenic ${ }^{27}$ control of gut smooth muscle cells, after surgical vagotomy ${ }^{25}$ or hiatal hernia repair, ${ }^{19}$ as well as in young women with anorexia nervosa. ${ }^{28}$

In the largest manometric study carried out so far in dyspeptic patients, ${ }^{7}$ a reduced contractility of the distal antrum was found in a slightly greater proportion $(70 \%)$ than that detected in our patients with chronic idiopathic dyspepsia $(60 \%)$. The stricter inclusion criteria adopted in the present study and, in particular, the exclusion of patients with diabetes and other possible secondary forms of gastroparesis may account for this difference.

Only a few studies have investigated gastrointestinal pressure activity in duodenal ulcer. Moore et $a l^{29}$ reported a numeric but not statistically significant decrease in interdigestive antral motility in five patients with healed duodenal ulcers compared with healthy controls. Manometric studies in patients with active duodenal ulcers have mainly focused on propagation of phasic contractions. ${ }^{30}{ }^{31}$ Comparison of these studies with our results is difficult, since the recording technique we used does not allow a reliable evaluation of duodenal and transpyloric propagation of pressure waves. Since gastric emptying in patients with active duodenal ulcers has been reported as accelerated ${ }^{16}$ or normal, ${ }^{32}$ postprandial antral hypomotility in our duodenal ulcer patients might be considered an unexpected result. Nevertheless, as previously mentioned, factors other than antral phasic contractility are important determinants of gastric emptying and may compensate in these patients for a decreased grinding activity of the distal antrum.

To the best of our knowledge, no direct measurement of the gastric motor response to feeding in gastric ulcer patients has previously been published. Gastric emptying of solids but not liquids was found to be delayed in gastric ulcer patients. ${ }^{33}$ Geldof $e t$ al observed, by electrogastrography, a lack of the normal increase in 
postprandial electrical signals in patients with symptomatic active gastric ulcer. ${ }^{34}$ Interdigestive gastric motor activities in gastric ulcer patients have received greater attention. A decrease in phasic gastric contractions in fasting gastric ulcer patients was recorded over 30 years ago by Garret et al, by intragastric balloon combined with a cineradiographic technique. ${ }^{3}$ In a more recent study, Miranda et al described both decreased antral contractility during phase III and a reduced number of active fronts with antral components. ${ }^{4}$ It is unlikely that our results are biased by a lack of age homogeneity among groups, since manometric studies previously carried out in 18 to 69 year old dyspeptic patients failed to detect any age related effect on antral contractility..$^{35}$

Our observations of basically similar motor disturbances in patients with organic and idiopathic dyspepsia argue against a role for gut dysmotility in the pathogenesis of peptic ulcer. In keeping with this concept, Garret et al observed improvement in gastric hypomotility in three patients after healing of the ulcer crater and resolution of the symptoms. ${ }^{3}$ The relation between gastrointestinal motor disorders and dyspeptic symptoms is far from established. Severe gastroparesis is sometimes asymptomatic $^{36}$ and, as previously shown ${ }^{7-9}$ and confirmed in the present study, dyspeptic symptoms are not invariably accompanied by detectable motor disorders in the distal antrum and proximal small bowel. Approximately $40 \%$ of our dyspeptic patients showed normal motor responses to feeding and no statistical correlation was found between symptom scores and the postprandial antral contractile responses to feeding. Psychogenic disorders are particularly frequent among dyspeptic patients with normal gastrointestinal manometry, ${ }^{7}$ but no attempt was made to investigate this aspect in our patients.

In this study, sporadic motor abnormalities only were observed in the proximal small bowel, and all the intestinal activity fronts seemed normal for propagation and configuration. Interestingly, the intestinal motor abnormalities (repetitive clustered contractions in two patients and a non-propagated burst of contractions in one patient) were recorded in $13 \%$ of the subjects complaining of symptoms compatible with the diagnosis of irritable bowel syndrome, but in none of those complaining of dyspeptic symptoms only. Similar results have recently been reported by Kerlin. ${ }^{9}$ Only $2 / 18$ of the chronic idiopathic dyspepsia patients we evaluated manometrically had abnormal intestinal motor patterns. Both complained of changes in bowel habits and diffuse abdominal bloating. A larger percentage of abnormal intestinal motor patterns was found in the Mayo Clinic series (30\%), in which subjects with symptoms of irritable bowel syndrome and associated metabolic and neurogenic diseases were also included. Episodes of clustered contractions were found in over $90 \%$ of the irritable bowel syndrome patients evaluated in two recent studies. ${ }^{3738}$ In both studies, intestinal motility was recorded for long periods of time and clustered contractions accounted for $12(11) \%^{36}$ to $34(7) \%^{38}$ of the total duration of phase II activity. Shorter recording times, such as those of the present study, can underestimate the occurrence of this motor pattern. This hypothesis is further substantiated by the results of a prolonged manometric study carried out by Kumar and Wingate on irritable bowel syndrome patients. ${ }^{39}$ During a 23 hour recording period, motor abnormalities were recorded in the small bowel of $8 / 22$ patients $(36 \%)$. Only a third of these (14\%) showed episodes of disordered motility during the first eight hours. This figure is very similar to that observed in our irritable bowel syndrome patients.

In conclusion, patients with both ulcer and non-ulcer dyspepsia show interdigestive and postprandial antral hypomotility, while abnormal intestinal motor patterns are only found in a limited number of patients, seemingly those with associated irritable bowel syndrome.

1 Barbara L, Camilleri M, Corinaldesi R, et al. Definition and investigation of dyspepsia. Consensus of an international investigation of dyspepsia. Consensus of an internatio

2 Talley NJ, Phillips SF. Non-ulcer dyspepsia: potential causes and pathophysiology. Ann Intern Med 1988; 108: 865-79.

3 Garrett JM, Summerskill WHJ, Code CF. Antral motility in patients with gastric ulcer. Am F Dig Dis 1966; 10: 780-9.

4 Miranda M, DeFilippi C, Valenzuela JE. Abnormalities of interdigestive motility complex and increased duodenogastric reflux in gastric ulcer patients. Dig Dis Sci 1985; 30: 16-21.

5 Rees WD, Miller LJ, Malagelada JR. Dyspepsia, antral motor dysfunction, and gastric stasis of solids. Gastroenterology 1980; 78: 360-5

6 Reboa G, Arnulfo G, DiSomma C. Prokinetic effects of cisapride on normal and reduced antroduodenal motility and reflexes. Curr Ther Res 1984; 36: 18-23.

7 Malagelada JR, Stangehellini V. Manometric evaluation of functional upper gut symptoms. Gastroenterology 1985; 88: functional

8 Camilleri M, Malagelada JR, Kao PC, Zinsmeister AR. Gastric and autonomic responses to stress in functional dyspepsia. Dig Dis Sci 1986; 31: 1169-77.

9 Kerlin P. Postprandial antral hypomotility in patients with idiopathic nausea and vomiting. Gut 1989; 30: 54-9.

10 Labo' G, Bortolotti M, Vezzadini P, Bonora G, Bersani G. Interdigestive gastroduodenal motility and serum motilin levels in patients with idiopathic delay in gastric emptying. Gastroenterology 1986; 90: 20-6.

11 Kelly KA. Motility of the stomach and gastroduodenal junction. In: Johnsons LR, ed. Physiology of the gastro intestinal tract. New York: Raven Press, 1981; 393-410.

12 Keane FB, DiMagno EP, Malagelada JR. Duodenogastric reflux in humans: its relationship to fasting antroduodenal reflux in humans: its relationship to fasting antroduodenal
motility and gastric, pancreatic, and biliary secretion. motility and gastric, pancreatic,

13 Rhodes J, Barnardo DE, Phillips SF, Rovelstad RA, Hofman AF. Increased reflux of bile into the stomach in patients with gastric ulcer. Gastroenterology 1966; 57: 241-52.

14 Camilleri M, Brown ML, Malagelada JR. Relationship between impaired gastric emptying and abnormal gastrointestinal motility. Gastroenterology 1986; 91: 94-9.

15 Nyrén $O$. Non-ulcer dyspepsia: a candidate motility disorder. Motility 1988; 3: 4-10.

16 Malagelada JR, Longstreth GF, Deering TB, Summerskill WH, Go VL. Gastric secretion and emptying after ordinary meals in duodenal ulcer. Gastroenterology 1977; 73: 989-94.

17 Manning AP, Thompson WG, Heaton KW, Morris AF. Towards positive diagnosis of the irritable bowel. $B M \dot{F}$ 1978; $2: 653-4$.

18 Stanghellini V, Corinaldesi R, Ghidini C, Ricci Maccarini M, Barbara L. Methodology of gastroduodenal manometry. In: Scarpignato C, Bianchi Porro G, eds. Clinical investigation of
gastric function. Frontiers of Gastrointestinal Research. Vol 17. gastric function. Frontiers of Gastr.

19 Stanghellini V, Malagelada JR. Gastric manometric abnormalities in patients with dyspeptic symptoms after fundoplication. Gut 1983; 24: 790-7.

20 Camilleri M, Malagelada JR, Stanghellini V, Zinsmeister AR, Kao PC, Choh HL. Dose-related effects of synthetic human B-endorphin and naloxone on fed gastrointestinal motility. Am 7 Physiol 1986; 251: G147-54.

21 Lam SK, Inseberg JI, Grossman MI, Lane WH, Hogan DL. Rapid gastric emptying in duodenal ulcer patients. Dig Dis Sci 1982; 27: 598-604.

22 Stanghellini V, Camilleri M, Malagelada JR. Chronic idiopathic intestinal pseudo-obstruction: clinical and idiopathic intestinal pseudo-obstruction: clinica

23 Summers RW, Anuras S, Green J. Jejunal manometry patterns in health, partial intestinal obstruction and pseudoin health, partial intestinal obstruction and
obstruction. Gastroenterology 1983;85: 1290-300.

24 Mearin F, Camilleri M, Malagelada JR. Pyloric dysfunction in diabetics with recurrent nausea and vomiting. Gastroenterology 1986; 90: 1919-25.

25 Malagelada JR, Rees WD, Mazzotta LJ, Go VL. Gastric motor abnormalities in diabetic and postvagotomy gastroparesis effect of metoclopramide and bethanecol. Gastroenterology 1980; 78: 286-93. 
26 Rees WD, Leigh RJ, Christofides ND, Bloom SR, Turnberg LA. Interdigestive motor activity in patients with systemic sclerosis. Gastroenterology 1982; 83: 575-80.

27 Camilleri M, Malagelada JR, Stanghellini V, Fealey RD, Sheps SG. Gastrointestinal motility disturbances in patients with orthostatic hypotension. Gastroenterolog 1985; 88: 1852-9.

28 Abell TL, Malagelada JR, Lucas AR, et al. Gastric electromechanical and neurohormonal function in anorexia nervosa. Gastroenterology 1987; 93: 958-65.

29 Moore SC Malagelada JR, Shorter RG, Zinsmeister AR. Interrelationships among gastric mucosal morphology, secretion, and motility in peptic ulcer disease. Dig Dis Sci secretion, and motil

30 Kerrigan DD, Houghton LA, Taylor ME, Read NW, Johnson AG. Disordered motility in duodenal ulcer disease. Gut 1989; 30: A1444.

31 Borgstrom S, Arborelius M. Duodenal motility pattern in duodenal ulcer disease. Scand F Gastroenterol 1978; 13: 34952.

32 Corinaldesi R, Stanghellini V, Paparo GF, Paternicò A, Rusticali AG Barbara L. Gastric acid secretion and gastric emptying of liquids in 99 male duodenal ulcer patients. Dig Dis Sci 1989; 34: 251-6.
33 Miller LJ, Malagelada JR, Longstreth GF, Go VL. Dysfunctions of the stomach with gastric ulceration. Dig Dis Sci 1980; 25: 857-64.

34 Geldof H, Van Der Schee EJ, Smout AJPM, Van De Merwe JP, Van Blankenstein M, Grashuis JL. Myoelectrical activity of the stomach in gastric ulcer patients: an electrogastrographic study. $\mathcal{F}$ Gastrointest Mot 1989; 1: $122-30$.

35 Fich A, Camiiieri M, Phillips SF. Effect of age on human gastric and small bowel motility. $\mathcal{F}$ Clin Gastroenterol 1989; 11: $416-20$.

36 Loo FD, Palmer DW, Soergel KH. Kalbfleisch JH, Wood $\mathrm{CM}$, Gastric emptying in patients with diabetes mellitus. GM, Gastric emptying in patients

37 Kellow JE, Phillips SF. Altered small bowel motility in irritable bowel syndrome is correlated with symptoms. Gastroenterology 1987; 92: 1885-93.

38 Kellow JE, Gill RC, Wingate DL. Prolonged ambulan recordings of small bowel motility demonstrate abnormalities in the irritable bowel syndrome. Gastroenterology 1990; 98: 1208-18.

39 Kumar D, Wingate DL. The irritable bowel syndrome: a paroxysmal motor disorder. Lancet 1985; ii: 973-7. 